\title{
Complete sputum smear monitoring among adults with pulmonary tuberculosis in central Uganda: evidence from a retrospective cohort study
}

\section{Norbert Adrawa}

The AIDS Support Organization

\section{Stephen Okoboi}

Infectious Diseases Institute, College of Health Sciences, Makerere University

\section{Alimah Komuhangi}

Institute of Public Health and Management, Clarke International University, Uganda

Jonathan Izudi ( $\square$ jonahzd@gmail.com )

Department of Community Health, Mbarara University of Science and Technology, Mbarara

\section{Ronald Nsubuga}

Institute of Public Health and Management, Clarke International University, Uganda

\section{Research Article}

Keywords: Bacteriologically confirmed pulmonary tuberculosis, smear-positive tuberculosis, Sputum smear monitoring, Uganda

Posted Date: June 4th, 2021

DOl: https://doi.org/10.21203/rs.3.rs-570869/v1

License: (c) (1) This work is licensed under a Creative Commons Attribution 4.0 International License. Read Full License 


\section{Abstract}

Background: People with bacteriologically confirmed pulmonary tuberculosis require sputum smear monitoring at 2, 5, and 6 months to establish treatment outcomes. However, there is limited information about sputum smear monitoring in Uganda, similar to other developing countries. We examined factors associated with complete sputum smear monitoring among persons with bacteriologically confirmed pulmonary TB aged $\geq 15$ years in central Uganda.

Methods: We retrospectively reviewed and abstracted data for persons with bacteriologically confirmed pulmonary TB initiated on treatment between January 2017 and December 2019 across 11 large TB units in Masaka district in central Uganda. Complete sputum smear monitoring was measured as the receipt of three sputum smear microscopy tests at 2,5, and 6 months of TB treatment. The data were summarized descriptively and the differences in the outcome with independent variables were examined using tests of statistical significance. The factors independently associated with the outcome were established using the modified Poisson regression analysis with robust standard errors, reported as adjusted risk ratio (aRR) along with the $95 \%$ confidence interval $(\mathrm{Cl})$.

Results: A total of 416 participants were enrolled, with a mean age of $37.3 \pm 12.9$ years. Of the participants, 290 (69.7) were males, 269 (64.7) were rural residents, and 128 (30.8\%) had complete sputum smear monitoring. Urban residence (aRR, 1.45; $95 \% \mathrm{Cl}, 1.12-1.90)$, treatment under the community-based directly observed therapy short-course strategy (DOTS) (aRR, 1.91; 95\% Cl, 1.25-2.92), and TB and human immunodeficiency virus (TB/HIV) comorbidity (aRR $0.45,95 \% \mathrm{Cl} 0.30-0.68$ ) were associated with complete sputum smear monitoring.

Conclusions: We observed a low magnitude of complete sputum smear monitoring among persons with bacteriologically confirmed pulmonary TB aged $\geq 15$ years in central Uganda. Urban residence and treatment under community-based DOTS are associated with a higher likelihood of complete sputum smear monitoring while TB/HIV co-infection is associated with a lower likelihood of complete sputum smear monitoring. At rural health facilities, there is a need to develop strategies to enhance the performance of sputum smear monitoring. Additionally, TB/HIV collaboration and the implementation of community-based DOTS should be strengthened to increase the performance of sputum smear monitoring.

\section{Background}

High morbidity and mortality posed by tuberculosis (TB) continue to be a global public health problem despite the availability of effective treatment. Globally, in 2019, 10 million people fell ill with TB disease and 1.4 million died, with the burden being highest in the sub-Saharan African region (1). In Uganda, approximately half of all persons diagnosed with pulmonary TB are bacteriologically confirmed pulmonary TB (2), the most infectious form of TB disease. Persons with bacteriologically confirmed pulmonary TB pose an enormous risk of TB transmission at household and community levels especially 
when they sneeze, cough, laugh, spit, sing, talk, or breathe (3). Therefore, proximity to these individuals puts one at an increased risk of TB infection, especially when they are not on treatment. The early diagnosis of pulmonary TB and initiation of treatment is advantageous in preventing onward transmission of TB. To establish a response to treatment, the Uganda National TB treatment guidelines recommend sputum smear monitoring at 2, 5, and 6 months (4), using sputum smear microscopy since GeneXpert and culture are expensive. Based on sputum smear examination results, persons with a negative test continue with the first-line TB treatment while those with a positive test result receive GeneXpert to exclude rifampicin resistance. When an individual has a positive sputum smear monitoring test result but is rifampicin sensitive, treatment adherence counseling and support is provided while those found rifampicin resistant are started on second-line treatment for multi-drug resistant TB. Good response to treatment is reflected by sputum smear conversion, a change in sputum smear test result from positive to negative. Furthermore, sputum smear monitoring is useful in establishing treatment failure, the emergence of multi-drug resistance, and establishing cure (3).

Uganda has a suboptimal cure rate of $51 \%$ (5) and a treatment success rate of $78 \%$ according to the most recent national data (6). These rates are far below the WHO desired targets of $85 \%$ cure rate and at least $90 \%$ treatment success rate $(7)$, respectively.

One of the reasons for the suboptimal cure rate is a low level of complete sputum smear monitoring among persons with bacteriologically confirmed pulmonary TB (8), and incomplete sputum smear monitoring is equally a marker for suboptimal treatment success. However, information about complete sputum smear monitoring across most countries in sub-Saharan Africa is limited. Studies show that a substantial proportion of people with bacteriologically confirmed pulmonary TB do not complete sputum smear monitoring (9-12) despite its positive impact on treatment outcomes (8). From literature, not being on directly observed therapy short-course strategy (DOTS) (11), being a male $(10,11)$, being unable to produce sputum, and experiencing longer waiting time at health facilities including inadequate patient health education on the importance, timing, and frequency of sputum smear monitoring $(9,11)$ are associated with incomplete sputum smear monitoring. We examined factors associated with complete sputum smear monitoring among people with bacteriologically confirmed pulmonary TB in Masaka district in central Uganda, a setting where program data show that majority of persons with bacteriologically confirmed pulmonary TB do not complete sputum smear monitoring.

\section{Methods And Materials}

\section{Study design and setting}

This retrospective cohort study involved the review of secondary data across 11 large public and privatenot-for profit health facilities in Masaka district in central Uganda. In Uganda, the first level of healthcare is Health Center ( $\mathrm{HC})$ II at the parish level followed by HC III at the sub-county level, HC IV at the county level, district hospital at the district level, and then regional and national referral hospitals at the district and national levels, respectively. Currently, there are five national referral hospitals, 14 regional referral 
hospitals, 169 general hospitals, 194 health center (HC) IVs, and the remaining are HC IIIs and HC. However, there are also five super-specialized hospitals in the country and two specialized institutes, the Uganda Heart Institute and the Uganda Cancer Institute (13).

The public health facilities included; Bukoto, Kamulegu, Bukeeri, Mpugwe, Buwunga, and Bukakata Health Center IIIs (HC IIIs), which are sub-county level health facilities. Also, Kyanamukaaka and Kiyumba HC IVs which are county-level health facilities, and Masaka Hospital, a regional level hospital were included. The private not-for-profit health facilities included Kitovu district hospital and Ssunga Health Centre III. Each of these study sites has a TB clinic that provides TB treatment and diagnostic services following the Uganda National TB and Leprosy Control Program (NTLP) Treatment guidelines. The diagnosis of drugsusceptible pulmonary TB using a GeneXpert occurs at HC IV and hospital levels of care which are sites with a GeneXpert testing machine. At HC II level of care, only sputum smear microscopy is performed to diagnose TB. However, sputum smear samples are collected for examination at a GeneXpert site to exclude rifampicin drug resistance. People with bacteriologically confirmed pulmonary TB receive 6months of anti-TB regimen in two phases. In the intensive phase, they receive 2 months of treatment that consist of Rifampicin (R), Isoniazid (H), Pyrazinamide (Z), and Ethambutol (E) administered as a fixeddose combination of tablets. In the continuation phase, they receive $\mathrm{RH}$ for 4 months as a fixed-dose combination of tablets. Sputum smear monitoring is performed using microscopy at 2, 5, and 6 months of the treatment.

\section{Eligibility criteria}

We included all persons aged $\geq 15$ years diagnosed with bacteriologically confirmed pulmonary TB and initiated treatment between January 2017 and December 2019. We excluded the following categories of persons with TB: 1) persons whose response to TB treatment was not monitored using sputum smear microscopy, namely persons with clinically diagnosed and extrapulmonary TB; and, 2) persons whose sputum smear monitoring status could not be established, either because they were transferred to another health facility or lost to follow-up.

\section{Study variables and measurements.}

Our outcome variable was complete sputum smear monitoring, measured on a binary scale. Persons who received all the three recommended sputum smear microscopy tests at 2, 5, and 6 months of TB treatment were regarded to have complete sputum smear monitoring and all the rest were regarded to have incomplete sputum smear monitoring. The independent variables included age, sex, TB/HIV comorbidity, and baseline bacilli load, type of person with bacteriologically confirmed pulmonary TB, availability of treatment supporter, residence, and type of DOTS. The health facility attributes included the level, type of ownership, and location.

\section{Data collection and processing}


We abstracted data from TB unit registers using a standardized data abstraction tool between July and August 2020. Before data collection, the data abstraction tool was pre-tested outside the study area and the data collectors received training about the study purpose, data abstraction, and responsible conduct of research. All the filled data abstraction tools were reviewed for completeness before entry in Epi-Data (14). To minimized data entry errors, quality control measures like skips, alerts, range, and legal values were employed in Epi-Data.

\section{Statistical data analysis}

The analysis was done in Stata version 15 (Stata Corp., College Station, Texas, USA). Frequencies and percentages were computed for categorical data and means with standard deviations for numerical data at the univariate analysis. Complete sputum smear monitoring was computed as the proportion of participants with three sputum smear microscopy examinations scheduled at 2, 5, and 6 months of TB treatment. In the bivariate analysis, the Chi-square test was employed to test differences in complete sputum smear monitoring with categorical data when all the cell counts were $\geq 5$, otherwise, Fisher's exact test was used.

Mean differences in complete sputum smear monitoring with numerical data were compared with the Student's t-test. The multivariate analysis included all variables with probability value ( $p$-value) less than $5 \%$ at bivariate analysis and significant variables from the literature particularly residence. The outcome was frequent so the odds ratio would overestimate the degree of association (15). Accordingly, we computed crude risk ratio (RR) and adjusted risk ratio (aRR) at multivariate analysis using the modified Poisson regression analysis with robust standard errors (16), and reported RR with the corresponding $95 \%$ confidence interval $(\mathrm{Cl})$. We did not report probability values ( $\mathrm{p}$-values) since they are less informative (17). Cls are sufficient for reporting the precision of the measure of effect and establishing statistical significance (17). Additionally, $\mathrm{Cl}$ is more informative than p-values (18) and is hence preferred in reporting the measure of effect (19-21).

\section{Ethical considerations}

Our study was reviewed and approved by the Clarke International University Research Ethics Committee (reference number CLARKE-2020-31). Administrative approval was obtained from the Masaka District Health Office.

\section{Results}

\section{Study profile}

There were 895 persons with TB registered for treatment across the study sites between January 2017 and December 2019 (Figure 1). Of this, a total of 479 persons were excluded with reasons: 1) 419 participants were ineligible because their response to treatment was monitored through clinical improvements but not sputum smear microscopy; and, 2) 60 participants were persons whose sputum 
smear status could not be established because they were either transferred to another health facility $(n=47)$ or were lost to follow-up $(n=13)$. Overall, we analyzed data for 416 participants.

\section{Distribution of participant characteristics}

The mean age of the 416 participants was $37.3 \pm 12.9$ years, with a range of $15-82$ years (Table 1 ). Participants with complete sputum smear monitoring were slightly older compared to those with incomplete sputum smear monitoring: $39.0 \pm 14.2$ versus $36.5 \pm 12.2(p=0.067)$. Table 1 further shows that most of the participants (36.1\%) were in the 25-34 age category, males (69.7\%), and persons with a new diagnosis of bacteriologically confirmed pulmonary TB (95.7\%). Over half (65.6\%) had received treatment under the community-based DOTS and $64.4 \%$ resided in a different sub-county to that of the health facility. Table 1 further shows that $64.7 \%$ of the participants were rural residents, less than half (41.6\%) were persons with TB/HIV (41.6\%), and the majority (81.0\%) had a treatment supporter.

\section{Level of incomplete sputum smear monitoring}

Of the 416 participants enrolled, 128 (30.8\%) had complete sputum smear monitoring. The majority of participants with complete sputum smear monitoring were from urban health facilities, had received treatment at the hospital level of care, and a public health facility. Both females and males had a comparable proportion of complete sputum smear monitoring: $26.2 \%$ versus $32.8 \%$ respectively, $p=$ 0.182 . We found statistically significant differences in complete sputum smear monitoring concerning the type of health facility ownership $(p=0.006)$, type of DOTS $(p<0.001)$, TB/HIV co-infection $(p<0.001)$, and treatment supporter availability $(p=0.048)$.

\section{Factors associated with the complete sputum smear monitoring}

Table 2 shows both the unadjusted and adjusted analyses findings. In the unadjusted analysis, community-based DOTS was associated with a higher likelihood of complete sputum smear monitoring (RR 2.39, 95\% Cl 1.60-3.58) while TB/HIV co-infection was associated with a lower likelihood of complete sputum smear monitoring (RR, $0.36 ; 95 \% \mathrm{Cl}, 0.24-0.53)$. However, having a treatment supporter ( $R R, 1.53 ; 95 \% \mathrm{Cl} 0.98-2.40)$, living in the same sub-county as the health facility (RR, $0.74 ; 95 \% \mathrm{Cl}, 0.53-$ 1.02), and being an urban resident (RR, $1.17 ; 95 \% \mathrm{Cl}, 0.87-1.57)$ were not associated with complete sputum smear monitoring. After adjusting for statistically significant and socially relevant variables namely residence and treatment supporter availability (Table 2), our data show that complete sputum smear monitoring was $45 \%$ more likely among urban residents compared to rural residents (aRR 1.45 $95 \% \mathrm{Cl} 1.12-1.90)$ and when treatment had occurred under community-based DOTS compared to facilitybased DOTS (aRR 1.91, 95\% Cl 1.25-2.92). Conversely, persons with TB/HIV were $55 \%$ less likely to complete sputum smear monitoring (aRR $0.45,95 \% \mathrm{Cl} 0.30-0.68)$. However, having a treatment supporter was not associated with complete sputum smear monitoring (aRR 1.21, 95\% Cl 0.78-1.88).

\section{Discussion}


Our study focused on complete sputum smear monitoring among persons with bacteriologically confirmed pulmonary TB in central Uganda. We found that a third of persons with bacteriologically confirmed pulmonary TB complete sputum smear monitoring, with completion being more likely among urban than rural residents and when treatment is under community-based DOTS compared to facilitybased DOTS, but less likely among persons with TB/HIV comorbidity.

The level of complete sputum smear monitoring in the present study is much lower than previously reported in Rwanda at 49.9\% (12) and across two rural districts in Uganda at 45\% (11) but comparable to $27.7 \%$ observed in a recent study in rural eastern Uganda (9). In general, the magnitude of complete sputum smear monitoring remains distant from the Uganda Ministry of Health target of $100 \%$ (all persons with bacteriologically confirmed pulmonary TB receiving three sputum smear microscopy examinations) [4]. The lower magnitude of complete sputum smear monitoring undermines efforts to ascertain response to treatment, detect treatment failure, and drug resistance. This will exacerbate TB morbidity and mortality at both the household and community levels since persons with bacteriologically confirmed pulmonary TB infect on average 10-15 persons per year (22). Given that TB control programs in sub-Saharan Africa have a suboptimal treatment success rate (23) and the positive impact of complete sputum smear monitoring on cure and treatment success rates (8), sputum smear monitoring should be a top priority for both the district and national TB control programs.

Our study shows that urban residents are more likely to complete sputum smear monitoring compared to rural residents. This could be due to easy access to health services in urban areas compared to rural areas.

This finding is consistent with previous studies which report sputum smear monitoring is less likely among rural residents compared to urban residents $(9,24)$. Accordingly, direct and indirect costs associated with access to TB care tend to negatively affect the continuity of care (25). It is important to recognize that in Uganda, access to health facilities continue to be a challenge in rural areas despite the availability of the Uganda National Health Policy framework which aims to achieve universal access to basic health care package within a $5 \mathrm{~km}$ radius (26). To date, the majority of the population lives $\geq 5$ kilometers from a health facility making access to healthcare difficult (27). Accordingly, the Uganda government decentralized the delivery of health services by using Village Health Teams, the lowest level of the formal health system. However, uptake of TB services in rural areas is still challenging [16]. This is because, at the lowest level of healthcare, multiple operational challenges such as low motivation, inadequate funding, and a low level of community involvement are prevalent $[14,17]$. Consequently, sputum smear monitoring appears not to be a priority. Another reason is inadequacies in staffing, supplies, reagents, and equipment to enable rural health facilities to perform follow-up sputum smear microscopy examinations (9).

Our finding of a higher likelihood of complete sputum smear monitoring under the community-based DOTS is not surprising. This is because DOTS enables supervised TB treatment and ensures compliance with treatment recommendations (28). Data from systematic reviews and meta-analysis show that the 
community-based DOTS is associated with better treatment outcomes namely treatment success rate $(29,30)$, higher treatment completion rate, and lower mortality and transfer-out rates compared to the facility-based DOTS (30). Our finding hence reinforces the need to strengthen the implementation of the community-based DOTS. Furthermore, the community-based DOTS allows the involvement of community support in TB treatment by establishing a community-based support system to enable treatment compliance and sputum smear monitoring (31).

Conversely, facility-based DOTS require individuals to visit the health facility on daily basis supervised treatment by a healthcare worker. This is logistically inefficient and ineffective given that persons with TB face physical and economic barriers (9).

Our data show that persons with TB/HIV are less likely to complete sputum smear monitoring. TB and HIV are overlapping epidemics hence healthcare providers must provide comprehensive information concerning the management of the comorbidity [18]. The present finding might be explained by an interplay of myriad factors like frequent TB/HIV clinic visits which are associated with both direct and indirect costs that compromise the continuity of care (32). Also, persons with TB/HIV tend to have high levels of stigma which negatively impact compliance to treatment guidelines or schedules (33). TB and HIV-related stigma combined with other factors like long travel distances equally influence compliance to treatment recommendations (33) and potentially results in missed appointments hence lost opportunity to monitor treatment response through sputum smear examinations. Our findings emphasize the need to strengthen TB/HIV collaborative activities to achieve better co-management and treatment outcomes.

\section{Study Strengths And Limitations}

Our study has several strengths. First, few studies (9-12) have focused on complete sputum smear monitoring in sub-Saharan Africa. Therefore, our study presents additional information about complete sputum smear monitoring among persons with bacteriologically confirmed pulmonary TB in sub-Saharan Africa. We analyzed data from all the large TB units so the findings are likely generalizable to the setting and other similar settings in Uganda and elsewhere. However, there are limitations to consider.

The analysis of secondary data is limited by the number of potential variables that influence complete sputum smear monitoring namely levels of education, counseling, income, and employment status among others. There is a possibility of missing or inaccurate data entries in the registers although attempts were made to verify sputum smear monitoring status using the TB laboratory register. The lack of qualitative data to explain the reasons for incomplete sputum smear monitoring from the perspectives of the participant, treatment supporter, and healthcare provider is another limitation to consider. Also, there is a possibility of selection bias by excluding lost to follow-up and transferred out participants especially if they have different characteristics from the included participants. However, it was logistically not possible to trace these participants and to establish their sputum smear monitoring status.

\section{Conclusions And Recommendations}


Our study shows that among persons with bacteriologically confirmed pulmonary TB aged $\geq 15$ years in central Uganda, the magnitude of complete sputum smear monitoring is low. Urban residence and treatment under community-based DOTs are associated with a higher likelihood of complete sputum smear monitoring while TB/HIV co-infection is associated with a lower likelihood of complete sputum smear monitoring. There is therefore a need to improve the performance of sputum smear monitoring in rural health facilities by addressing existing barriers and strengthening TB/HIV collaborative activities including the implementation of community-based DOTS.

\section{List Of Abbreviations}

aRR: Adjusted risk ratio.

DOTS: Directly Observed Therapy Short Course

HIV: Human Immunodeficiency Virus.

RR: Unadjusted risk ratio.

\section{Declarations}

\section{Ethics approval and consent to participate}

This study was approved by the Clarke International University Research Ethics Committee (reference number CLARKE-2020-31). We received a waiver of informed consent Clarke International University Research Ethics Committee because it was logistically impractical and inefficient given that the data were collected retrospectively. We confirm that all the methods were performed in accordance with the relevant guidelines and regulations.

\section{Consent for publication}

Not applicable.

\section{Availability of data and materials}

The datasets used and/or analyzed during the current study are available from the corresponding author on reasonable request.

\section{Competing interests.}

The authors declare that they have no competing interests

\section{Funding}

None. 


\section{Author contributions}

RN and JI: Study conception and design. RN: Acquisition of data. JI and SO: Analysis and interpretation of data. RN, NA, SO, AK, Jl: Drafting of manuscript. SO and Jl: Critical revision: RN, NA, SO, AK, JI: Final approval of the manuscript.

\section{Acknowledgments}

Clarke International University Research Ethics Committee is hereby acknowledged for the wonderful review and feedback. The District Health Office, Masaka district, and the Head of the respective study sites are also appreciated for their support during the study. We thank the Research Assistants as well for their dedication and support.

\section{References}

1. World Health Organization. Global Tuberculosis Report 2020. Geneva, Switzerland: 2020.

2. Republic of Uganda. National Tuberculosis and Leprosy Control Program: Revised National Strategic Plan 2015/16-2019/20. Kampala, Uganda: Ministry of Health, 2017.

3. World Health Organization. Guidelines for treatment of drug-susceptible tuberculosis and patient care. 2017.

4. Hopewell PC, Pai M, Maher D, Uplekar M, Raviglione MC. International standards for tuberculosis care. The Lancet infectious diseases. 2006;6(11):710-25.

5. Republic of Uganda. National Tuberculosis and Leprosy Control Program: Revised National Strategic Plan 2015/16-2019/20. Kampala, Uganda: 2017.

6. Republic of Uganda. Annual health sector performance report: financial year 2019/2020. Kampala, Uganda: Ministry of Health, Uganda., 2020.

7. World Health Organization. Treatment of tuberculosis: guidelines for nationl programmes: World Health Organization; 2003.

8. Izudi J, Tamwesigire IK, Bajunirwe F. Does completion of sputum smear monitoring have an effect on treatment success and cure rate among adult tuberculosis patients in rural Eastern Uganda? A propensity score-matched analysis. PloS one. 2019;14(12):e0226919.

9. Izudi J, Tamwesigire IK, Bajunirwe F. Treatment supporters and level of health facility influence completion of sputum smear monitoring among tuberculosis patients in rural Uganda: A mixedmethods study. International journal of infectious diseases : IJID : official publication of the International Society for Infectious Diseases. 2020;91:149-55.

10. Harries A, Gausi F, Salaniponi F. When are follow-up sputum smears actually examined in patients treated for new smear-positive pulmonary tuberculosis? The international journal of tuberculosis and lung disease. 2004;8(4):440-4. 
11. Nakaggwa P, Odeke R, Kirenga B, Bloss E. Incomplete sputum smear microscopy monitoring among smear-positive tuberculosis patients in Uganda. The International Journal of Tuberculosis and Lung Disease. 2016;20(5):594-9.

12. Kayigamba FR, Bakker MI, Mugisha V, Gasana M, van der Loeff MFS. Sputum completion and conversion rates after intensive phase of tuberculosis treatment: an assessment of the Rwandan control program. BMC Research notes. 2012;5(1):1-7.

13. Ssebwami Javira. Massive! Uganda's health sector delivering service with confidence as citizens reap from infrastructure investiment (Part II). 2020.

14. Lauritsen J. EpiData (version 3.1). A comprehensive tool for validated entry and documentation of data. 2004.

15. Schmidt CO, Kohlmann T. When to use the odds ratio or the relative risk? International journal of public health. 2008;53(3):165.

16. Cameron AC, Trivedi PK. Regression-based tests for overdispersion in the Poisson model. Journal of econometrics. 1990;46(3):347-64.

17. Attia A. Why should researchers report the confidence interval in modern research. Middle East Fertil Soc J. 2005;10(1):78-81.

18. Gupta SK. The relevance of confidence interval and P-value in inferential statistics. Indian journal of pharmacology. 2012;44(1):143.

19. Akobeng AK. Confidence intervals and p-values in clinical decision making. Acta Paediatrica. 2008;97(8):1004-7.

20. Ranstam J. Why the P-value culture is bad and confidence intervals a better alternative. Elsevier; 2012.

21. Halsey LG. The reign of the p-value is over: what alternative analyses could we employ to fill the power vacuum? Biology letters. 2019;15(5):20190174.

22. World Health Organiation. Tuberculosis: key facts Geneva, Switzerland: WHO; 2020 [cited 2020 May 12,]. Available from: https://www.who.int/news-room/fact-sheets/detail/tuberculosis.

23. Izudi J, Semakula D, Sennono R, Tamwesigire IK, Bajunirwe F. Treatment success rate among adult pulmonary tuberculosis patients in sub-Saharan Africa: a systematic review and meta-analysis. BMJ Open. 2019;9(9):e029400.

24. Musaazi J, Kiragga A, Castelnuovo B, Kambugu A, Bradley J, Rehman A. Tuberculosis treatment success among rural and urban Ugandans living with HIV: a retrospective study. Public health action. 2017;7(2):100-9.

25. Tadesse T, Demissie M, Berhane $Y$, Kebede $Y$, Abebe M. Long distance travelling and financial burdens discourage tuberculosis DOTs treatment initiation and compliance in Ethiopia: a qualitative study. BMC Public Health. 2013;13:424.

26. Republic of Uganda. Health Sector Development Plan 2015/16-2019/2020. Kampala, Uganda: Ministry of Health, 2015. 
27. Republic of Uganda. Annual health sector performance report: financial year 2017/2018. Kampala, Uganda: Ministry of Health, Uganda., 2018.

28. Organization WH. Companion handbook to the WHO guidelines for the programmatic management of drug-resistant tuberculosis: World Health Organization; 2014.

29. Wright CM, Westerkamp L, Korver S, Dobler CC. Community-based directly observed therapy (DOT) versus clinic DOT for tuberculosis: a systematic review and meta-analysis of comparative effectiveness. BMC Infect Dis. 2015;15:210.

30. Zhang H, Ehiri J, Yang H, Tang S, Li Y. Impact of Community-Based DOT on Tuberculosis Treatment Outcomes: A Systematic Review and Meta-Analysis. PloS one. 2016;11(2):e0147744.

31. Mafigiri DK, McGrath JW, Whalen CC. Task shifting for tuberculosis control: a qualitative study of community-based directly observed therapy in urban Uganda. Global Public Health. 2012;7(3):27084.

32. Gebremariam MK, Bjune GA, Frich JC. Barriers and facilitators of adherence to TB treatment in patients on concomitant TB and HIV treatment: a qualitative study. BMC public health. 2010;10(1):19.

33. Daftary A, Padayatchi N. Social constraints to TB/HIV healthcare: accounts from coinfected patients in South Africa. AIDS care. 2012;24(12):1480-6.

\section{Tables}

Table 1: Relationship between participant's characteristics and complete sputum smear monitoring. 


\begin{tabular}{|c|c|c|c|c|c|}
\hline \multirow[t]{2}{*}{ Variable } & \multirow[t]{2}{*}{ Level } & \multirow{2}{*}{$\begin{array}{l}\text { Overall } \\
(n= \\
416)\end{array}$} & \multicolumn{2}{|c|}{$\begin{array}{l}\text { Complete sputum smear } \\
\text { monitoring }\end{array}$} & \multirow[t]{2}{*}{$P$ value } \\
\hline & & & $\begin{array}{l}\text { No } \\
(n=288)\end{array}$ & $\begin{array}{l}\text { Yes } \\
(n=128)\end{array}$ & \\
\hline \multirow[t]{2}{*}{ Health facility location } & Rural & $\begin{array}{l}137 \\
(32.9)\end{array}$ & $101(35.1)$ & $36(28.1)$ & \multirow[t]{2}{*}{0.164} \\
\hline & Urban & $\begin{array}{l}279 \\
(67.1)\end{array}$ & $187(64.9)$ & $92(71.9)$ & \\
\hline \multirow[t]{2}{*}{ Health facility level } & Health center & $\begin{array}{l}137 \\
(32.9)\end{array}$ & $101(35.1)$ & $36(28.1)$ & \multirow[t]{2}{*}{0.164} \\
\hline & Hospital & $\begin{array}{l}279 \\
(67.1)\end{array}$ & $187(64.9)$ & $92(71.9)$ & \\
\hline \multirow[t]{2}{*}{$\begin{array}{l}\text { Type of health facility } \\
\text { ownership }\end{array}$} & $\begin{array}{l}\text { Private-not- } \\
\text { for profit }\end{array}$ & $\begin{array}{l}21 \\
(5.1)\end{array}$ & $20(6.9)$ & $1(0.8)$ & \multirow[t]{2}{*}{0.006} \\
\hline & Government & $\begin{array}{l}395 \\
(95.0)\end{array}$ & $268(93.1)$ & $127(99.2)$ & \\
\hline \multirow[t]{6}{*}{ Age group (years) } & $15-24$ & $\begin{array}{l}52 \\
(12.5)\end{array}$ & $38(13.2)$ & $14(10.9)$ & 0.368 \\
\hline & $25-34$ & $\begin{array}{l}150 \\
(36.1)\end{array}$ & $108(37.5)$ & $42(32.8)$ & \\
\hline & $35-44$ & $\begin{array}{l}104 \\
(25.0)\end{array}$ & $70(24.3)$ & $34(26.6)$ & \\
\hline & $45-54$ & $\begin{array}{l}63 \\
(15.1)\end{array}$ & $45(15.6)$ & $18(14.1)$ & \\
\hline & $>55$ & $\begin{array}{l}47 \\
(11.3)\end{array}$ & $27(9.4)$ & $20(15.6)$ & \\
\hline & Mean & $\begin{array}{l}37.3 \\
\pm 12.9\end{array}$ & $36.5 \pm 12.2$ & $39.0 \pm 14.2$ & 0.067 \\
\hline \multirow[t]{2}{*}{ Sex } & Female & $\begin{array}{l}126 \\
(30.3) \\
\end{array}$ & $93(73.8)$ & $33(26.2)$ & 0.182 \\
\hline & Male & $\begin{array}{l}290 \\
(69.7)\end{array}$ & $195(67.2)$ & $95(32.8)$ & \\
\hline \multirow[t]{2}{*}{ Type of person with BC-PTB } & Retreatment & $\begin{array}{l}18 \\
(4.3)\end{array}$ & $9(50.0)$ & $9(50.0)$ & 0.071 \\
\hline & New & $\begin{array}{l}398 \\
(95.7)\end{array}$ & $279(70.1)$ & $119(29.9)$ & \\
\hline \multirow[t]{2}{*}{ Type of DOTS } & $\begin{array}{l}\text { Facility- } \\
\text { based }\end{array}$ & $\begin{array}{l}143 \\
(34.4)\end{array}$ & $\begin{array}{l}120 \\
(83.9)\end{array}$ & $23(16.1)$ & $<0.001$ \\
\hline & $\begin{array}{l}\text { Community- } \\
\text { based }\end{array}$ & $\begin{array}{l}273 \\
(65.6)\end{array}$ & $168(61.5)$ & $105(38.5)$ & \\
\hline $\begin{array}{l}\text { Lives in the same sub-county as } \\
\text { the health facility }\end{array}$ & No & $\begin{array}{l}268 \\
(64.4)\end{array}$ & $117(61.5)$ & $91(71.1)$ & 0.058 \\
\hline
\end{tabular}




\begin{tabular}{|l|l|l|l|l|l|} 
& & & & \\
\hline & Yes & $\begin{array}{l}148 \\
(35.4)\end{array}$ & $111(38.5)$ & $37(28.9)$ & \\
\hline Residence & Rural & $\begin{array}{l}269 \\
(64.7)\end{array}$ & $191(66.3)$ & $78(60.9)$ & 0.289 \\
\hline & Urban & $\begin{array}{l}147 \\
(35.3)\end{array}$ & $97(33.7)$ & $50(39.1)$ & \\
\hline TB/HIV & No & $\begin{array}{l}243 \\
(58.4)\end{array}$ & $141(58.3)$ & $102(42.0)$ & $<0.001$ \\
\hline & Yes & $\begin{array}{l}173 \\
(41.6)\end{array}$ & $147(85.0)$ & $26(15.0)$ & \\
\hline Treatment supporter & No & $\begin{array}{l}79 \\
(19.0)\end{array}$ & $62(78.5)$ & $17(21.5)$ & 0.048 \\
\hline & Yes & $\begin{array}{l}337 \\
(81.0)\end{array}$ & $226(67.1)$ & $111(32.9)$ & \\
\hline
\end{tabular}

Table 2: Factors associated with complete sputum smear monitoring at unadjusted and adjusted analysis. 


\begin{tabular}{|c|c|c|c|c|c|}
\hline \multirow[b]{3}{*}{ Variable } & \multirow[b]{3}{*}{ Level } & \multicolumn{4}{|c|}{$\begin{array}{l}\text { Modified Poisson regression } \\
\text { analysis }\end{array}$} \\
\hline & & \multicolumn{2}{|c|}{$\begin{array}{l}\text { Unadjusted } \\
\text { analysis }\end{array}$} & \multicolumn{2}{|c|}{$\begin{array}{l}\text { Adjusted } \\
\text { analysis }\end{array}$} \\
\hline & & RR & $95 \% \mathrm{CI}$ & aRR & $\begin{array}{l}95 \% \\
\mathrm{CI}\end{array}$ \\
\hline \multirow{2}{*}{$\begin{array}{l}\text { Lives in the same sub-county as the } \\
\text { health facility }\end{array}$} & No & 1 & & & \\
\hline & Yes & 0.74 & $\begin{array}{l}(0.53- \\
1.02)\end{array}$ & & \\
\hline \multirow[t]{2}{*}{ Residence } & Rural & 1 & & 1 & \\
\hline & Urban & 1.17 & $\begin{array}{l}(0.87- \\
1.57)\end{array}$ & $1.45^{*}$ & $\begin{array}{l}(1.12- \\
1.90)\end{array}$ \\
\hline \multirow[t]{2}{*}{ Type of DOTS } & Facility-based & 1 & & & \\
\hline & $\begin{array}{l}\text { Community- } \\
\text { based }\end{array}$ & $2.39 * * *$ & $\begin{array}{l}(1.60- \\
3.58)\end{array}$ & $1.91 * *$ & $\begin{array}{l}(1.25- \\
2.92)\end{array}$ \\
\hline \multirow[t]{2}{*}{ Persons with TB/HIV } & No & 1 & & 1 & \\
\hline & Yes & $0.36 * * *$ & $\begin{array}{l}(0.24- \\
0.53)\end{array}$ & $0.45^{* * *}$ & $\begin{array}{l}(0.30- \\
0.68)\end{array}$ \\
\hline \multirow[t]{2}{*}{ Health facility ownership } & $\begin{array}{l}\text { Private-not-for } \\
\text { Profit }\end{array}$ & 1 & & & \\
\hline & Public & 6.75 & $\begin{array}{l}(0.99- \\
45.96)\end{array}$ & & \\
\hline \multirow[t]{2}{*}{ Treatment supporter } & No & & & & \\
\hline & Yes & 1.53 & $\begin{array}{l}(0.98- \\
2.40)\end{array}$ & 1.21 & $\begin{array}{l}(0.78- \\
1.88)\end{array}$ \\
\hline
\end{tabular}

Note: 1) Statistical significance codes at $5 \%: * p<0.05, * * p<0.01,{ }^{* * *} p<0.001$; 2) DOTS: Directly observed therapy short course strategy; 3) RR: Unadjusted risk ratio; 4) aRR: Adjusted risk ratio; 5)

\section{Figures}




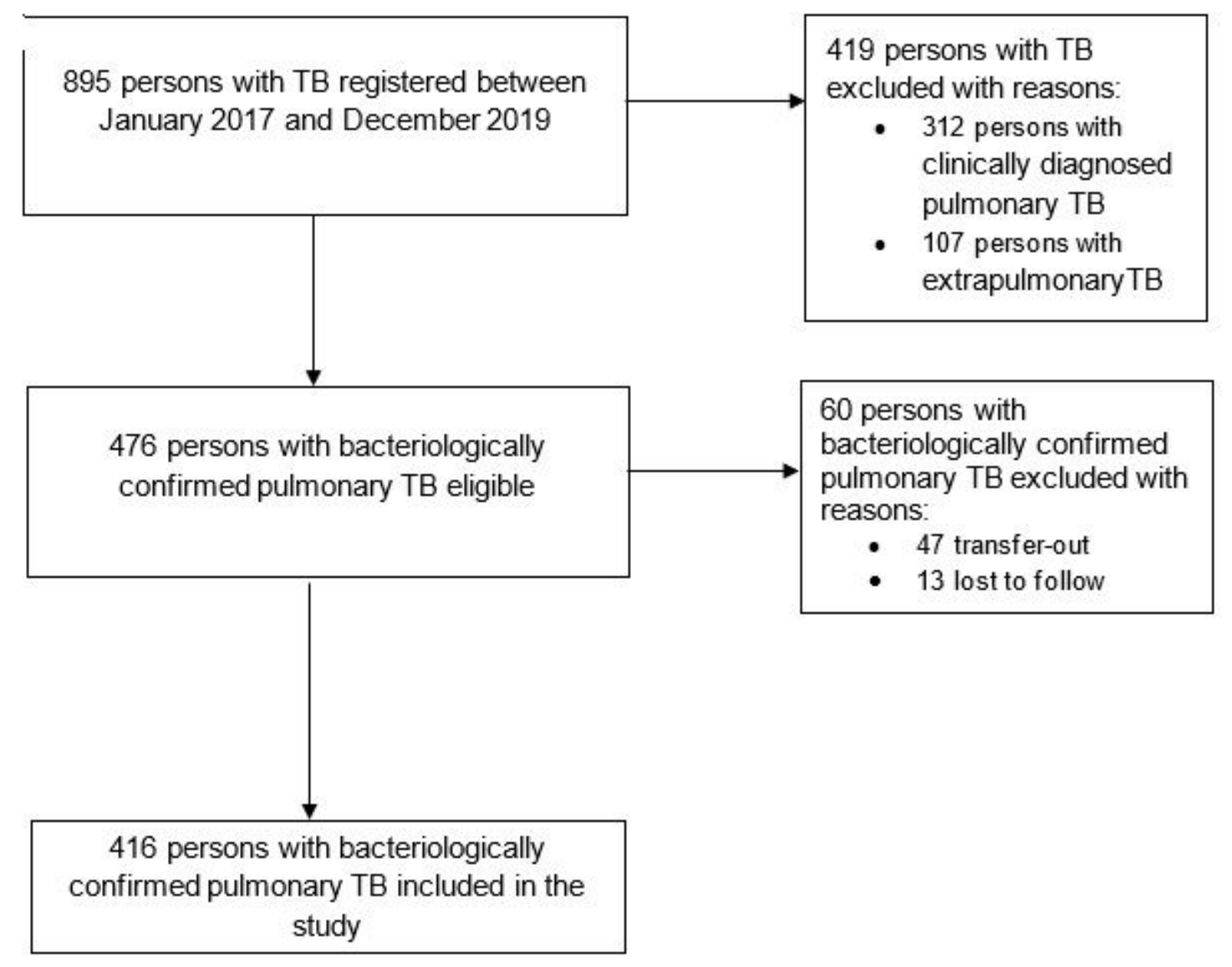

Figure 1

Study profile for complete sputum smear monitoring among persons with bacteriologically confirmed pulmonary TB in Masaka district in central Uganda. 